\title{
Venous Air Embolism Not Amniotic Fluid Embolism
}

\author{
Charles Her, M.D. \\ Inje University Haeundae Paik Hospital, Busan, Korea
}

Dear Editor:

I read the case report by Kang et al.[1] published in the Journal with interest. In their report, amniotic fluid embolism developed in a 41-year-old woman who underwent laparoscopic repair of bladder injury and closure of a perforated uterine wall, complicating dilatation and curettage for the second trimester termina-tion of pregnancy. The hypoxia this patient developed was so severe that authors had to use extracorporeal membrane oxygenation (ECMO) to save the patient's life. However, the diagnosis authors made deserves some comments.

The cardinal findings of amniotic fluid embolism are hypoxia, circulatory shock, altered mental status, and disseminated intravascular coagulation (DIC).[2] Hypoxia is abrupt in onset, rapidly deteriorates, and takes a fulminant course. The initial hypoxia is likely due to a severe ventilation and perfusion mismatching, caused by a profound right ventricular dysfunction.[3] Initially, left ventricular function is usually normal, but may deteriorate as a result of hypoxia and ischemia.[3] Cardiogenic pulmonary edema caused by a severe left ventricular dysfunction can also contribute to hypoxia. A later phase of hypoxia can develop in patients who survive the first several hours of catastrophic event. As a noncardiogenic pulmonary edema coincident with improvement in left ventricular function, inflammatory responses-induced pulmonary edema such as capillary leak syndrome contributes to the late hypoxia. This noncardiogenic pulmonary edema tends to resolve more rapidly than the typical course of acute respiratory distress syndrome.[2] Thus, hypoxia is usually managed with mechanical ventilatory support using high $\mathrm{FiO}_{2}$ and PEEP, not requiring veno-venous mode of ECMO, unless there is an accompanying circulatory collapse for which veno-arterial mode of ECMO is required. The time course of the development of acute hypoxic respiratory failure in the patient presented by Kang et al.[1] is different from that of amniotic fluid embolism. The authors had apparently some time to take a few chest radiographs to evaluate the situation at the onset and afterward the veno-venous ECMO had to be run for 19 days, indicating that the acute hypoxic res-piratory failure did not progress so rapidly as it would in the case of amniotic fluid embolism and it lasted that long. In previous reports, in which veno-arterial ECMO or cardiopulmonary bypass was used in patients with amniotic fluid embolism, all patients were able to be weaned off both circulatory and respiratory
Received January 26, 2016

Revised on February 15, 2016

Accepted on February 15, 2016

\section{Charles Her}

Inje University Haeundae Paik Hospital, 875, Haeun-daero, Haeundae-gu, Busan 48108, Korea

Tel: +82-51-797-0461

Fax: +82-51-797-0499

E-mail: charles6133@msn.com

*No potential conflict of interest relevant to this article was reported. 
support within 1 or 2 days.[4-6] More important is that there was no circulatory collapse in the case reported by Kang et al.[1] Circulatory shock is another early manifestation of amni-otic fluid embolism, and it is uniformly present in severe cases,[2] requiring veno-ar-terial mode of ECMO or cardiopulmonary bypass pump for successful resuscitation.[3,4] Hypotension results from impaired filling of the left ventricle associated with right ventricular failure, which is caused by pulmonary vasoconstriction, and a shift of the interventricular septum. Left ventricular dysfunction may get worse due to hypox-ia and ischemia.[3] Without the extracorporeal mechanical circulatory support such as venoarterial ECMO or cardiopulmonary bypass pump, cardiopulmonary resusci-tation for amniotic fluid embolism has not been successful in most cases.[3,7]

Coagulation disorders are a prominent feature of the amniotic fluid embolism. DIC is present in more than $83 \%$ of patients with amniotic fluid embolism.[8] In the patient reported by Kang et al.[1] however, fibrinogen, prothrombin time, active-ted thromboplastin time, and platelet count were all within normal range, indicating that there was no DIC. In addition, there was apparently no gross vaginal hemor-rhage, either. Slightly elevated D-dimer and fibrin degradation products levels do not necessarily indicate the presence of DIC. Many conditions other than DIC, such as trauma, recent surgery or venous thromboembolism are associated with elevated fibrin degradation products and Ddimer.[9]

With a long-lasted hypoxia alone, without accompanying DIC and circulatory collapse, it is not likely that the patient in the report of Kang et al.[1] had amniotic fluid embolism. Instead, it is most likely that the patient developed venous air embo-lism during the laparoscopic surgery. Venous air embolism has been reported to be associated with Cesarean section.[10,11] The incidence may rise up to $97 \%$ during Cesarean section.[12] It has been indicated that the uterine venous sinuses are the-oretically vulnerable to the entrance of air, especially in the presence of placenta or during manual extraction of the placenta.[13] Laparoscopic procedure, particularly laparoscopic hysterectomy has been reported to be associated with a high incidence of venous air embolism $(100 \%)$ in a various degree.[14] The patient in the report of Kang et al.[1] underwent a laparoscopic repair of the perforated gravid uterus of 19 weeks gestation before the patient developed acute hypoxic respiratory failure. Tak-en together, the patient was in the most vulnerable situation for the venous air embo-lism to develop. There are evidences that the venous air embolism induces ische-mia-reperfusion injury of the lung.[15,16] Chest radiographic findings of acute pulmo-nary edema caused by venous air embolism may vary from simple butterfly type of distribution to diffuse pulmonary edema, depending on the degree of lung injury.[17] Chest radiograph shown in Fig. 1B, taken 12 hours after dilatation and curettage in the report of Kang et al.[1] seems to be a simple butterfly type of distribution of pul-monary edema, consistent with venous air embolisminduced acute lung injury, and chest radiograph shown in Fig. 1C, taken 20 hours after the procedure, seems to be a diffuse pulmonary edema, which is also consistent with venous air embolism-induced acute lung injury, indicating more progressed lung injury.

In conclusion, it is not likely that the patient in the report of Kang et al.[1] had amniotic fluid embolism. The most likely explanation for the acute hypoxic respiratory failure in that case is the development of venous air embolisminduced acute lung injury.

\section{References}

1) Kang HS, Lee HY, Lee HY, Kim SC: Successful application of extracorporeal membrane oxygenation for a patient with clinical amniotic fluid embolism. Korean J Crit Care Med 2015; 30: 303-7.

2) Moore J, Baldisseri MR: Amniotic fluid embolism. Crit Care Med 2005; 33(10 Suppl): S279-85.

3) Ecker JL, Solt K, Fitzsimons MG, MacGillivray TE: Case records of the Massachusetts General Hospital. Case 40-2012: A 43-year-old woman with cardiorespiratory arrest after a cesarean section. N Engl J Med 2012; 367: 2528-36.

4) Stanten RD, Iverson LI, Daugharty TM, Lovett SM, Terry C, Blumenstock E: Amniotic fluid embolism causing catastrophic pulmonary vasoconstriction: diagnosis by transesophageal echocardiogram and treatment by cardiopulmonary bypass. Obstet Gynecol 2003; 102: 496-8.

5) Shen HP, Chang WC, Yeh LS, Ho M: Amniotic fluid 
embolism treated with extracorporeal membrane oxygenation: a case report. J Reprod Med 2009; 54: 706-8.

6) Hsieh YY, Chang CC, Li PC, Tsai HD Tsai CH; Successful application of extracorporeal membrane oxygenation and intra-aortic balloon counterpulsation as lifesaving therapy for a patient with amniotic fluid embolism. Am J Obstet Gynecol 2000; 183: 496-7.

7) Price TM, Baker VV, Cefalo RC: Amniotic fluid embolism. Three case reports with a review of the literature. Obstet Gynecol Surv 1985; 40: 462-5.

8) Gist RS, Stafford IP, Leibowitz, Beilin Y: Amniotic fluid ambolism. Anesth Analg 2009; 108: 1599-602.

9) Levi M, Toh CH, Thachil J, Watson HG: Guidelines for the diagnosis and management of disseminated intravascular coagulation. British Committee for Standards in Haematology. Br J Haematol 2009, 145: 24-33.

10) Younker D, Rodriguez V, Kavanaugh J: Massive air embolism during cesarean section. Anesthesiology 1986; 65: 77-9.

11) Kim CS, Liu J, Kwon JY, Shin SK, Kim KJ: Venous air embolism during surgery, especially cesarean delivery. J Korean Med Sci 2008; 23: 753-61.

12) Lew TW, Tay DH, Thomas E: Venous air embolism during cesarean section: more common than previously thought. Anesth Analg 1993; 73: 448-52.

13) Durant TM, Long J, Oppenheimer MJ: Pulmonary (venous) air embolism. Am Heart J 1947; 33: 269-81.

14) Kim CS, Kim JY, Kwon JY, Choi SH, Na S, An J, et al: Venous air embolism during total laparoscopic hysterectomy: comparison to total abdominal hysterectomy. Anesthesiology 2009; 111: 50-4.

15) Peng CK, Huang KL, Wu CP, Li MH, Lin HI, Hsu CW, et al: The role of mild hypothermia in air embolisminduced acute lung injury. Anesth Analg 2010; 110: $1336-42$

16) Chu SJ, Lee TY, Yan HC, Lin SH, Li MH: L-Arginine prevents air embolism-induced acute lung injury in rats. Crit Care Med 2005; 33: 2056-60.

17) Kizer KW, Goodman PC: Radiologic manifestation of venous air embolism. Radiology 1982; 144: 35-9. 